\section{Use of autogenous bone and beta-tricalcium phosphate in maxillary sinus lifting: histomorphometric study and immunohistochemical assessment of RUNX2 and VEGF}

R. S. Pereira, L. F. Gorla, F. B. J. D. Boos, R. Okamoto, I. R. Garcia Júnior, E. Hochuli-Vieira: Use of autogenous bone and beta-tricalcium phosphate in maxillary sinus lifting: histomorphometric study and immunohistochemical assessment of RUNX2 and VEGF. Int. J. Oral Maxillofac. Surg. 2017; 46: 503-510. (C) 2017 International Association of Oral and Maxillofacial Surgeons. Published by Elsevier Ltd. All rights reserved.

Abstract. The aim of this study was to compare the use of beta-tricalcium phosphate $(\beta$-TCP) (chronOS) with autogenous bone grafts alone in maxillary sinus elevation surgery. The test samples were $\beta$-TCP alone, $\beta$-TCP mixed with autogenous bone grafts $(1: 1)$, and autogenous bone grafts alone. Twelve maxillary sinuses were grafted with $\beta$-TCP (group 1), nine with $\beta$-TCP + autogenous bone graft (group 2 ), and 12 with autogenous bone graft (group 3). After 6 months, biopsies were obtained concurrent to the placement of dental implants; these were subjected to histomorphometric analysis and immunohistochemical analysis for runt-related transcription factor 2 (RUNX2) and vascular endothelial growth factor (VEGF). The average bone formation in group 1 was $46.3 \pm 11.6 \%$ in the pristine bone region, $47.6 \pm 9.9 \%$ in the intermediate region, and $44.8 \pm 22.1 \%$ in the apical region; in group 2, values were $35.0 \pm 15.8 \%, 32.5 \pm 13.7 \%$, and $32.8 \pm 16.0 \%$, respectively; in group 3 , values were $43.1 \pm 16.0 \%, 31.0 \pm 13.0 \%$, and $46.1 \pm 16.3 \%$, respectively. Immunostaining of samples in group 2 showed high cellular activity and immature bone; this differed from groups 1 and 3 , in which mature bone was demonstrated. Thus, this study showed that $\beta$-TCP presents the same behaviour as autogenous bone graft, which makes it a good bone substitute.
R. S. Pereira ${ }^{1}$, L. F. Gorla ${ }^{2}$, F. B. J. D. Boos ${ }^{2}$, R. Okamoto ${ }^{1}$, I. R. Garcia Júnior ${ }^{1}$, E. Hochuli-Vieira ${ }^{2}$

${ }^{1}$ Araçatuba Dental School, Universidade Estadual Paulista - UNESP, Araçatuba, São Paulo, Brazil; ${ }^{2}$ Araraquara Dental School, Universidade Estadual Paulista - UNESP, Araraquara, São Paulo, Brazil
Key words: maxillary sinus; bone graft; immunohistochemistry.

Accepted for publication 3 January 2017 Available online 6 February 2017 
The use of dental implants to restore the occlusion is one of the most frequently performed treatments in oral surgery today. However, in some cases, bone resorption prevents implant placement owing to the lack of bone height and thickness. In the posterior maxillary bone, sinus pneumatization can also restrict dental implant placement. ${ }^{1,2}$ The surgical procedure involving elevation of the Schneiderian membrane and the placement of bone substitutes, which have been researched extensively, enables the bone height to be re-established. . $^{3,4}$

The ideal bone graft should provide a three-dimensional (3D) matrix to support the necessary cells that enable bone healing and resorption..$^{5}$ Among the existing biomaterials (allogeneic bone graft, xenograft, and alloplastic materials), the autogenous bone graft is the only one that is able to initiate biological events culminating in osteogenesis, serving as an osteoinductor and osteoconductor. ${ }^{6-10}$ Furthermore, the autogenous bone graft contains osteoblastic cells, undifferentiated mesenchymal cells, osteoclasts, and growth factors. ${ }^{11}$

For intraoral procedures, the best location for autogenous bone graft harvesting is the oral cavity; however, the amount of bone graft harvested may be insufficient for requirements. ${ }^{12}$ Biomaterials thus represent promising substitutes for the autogenous bone graft in maxillary bone augmentation. However, such biomaterials have to be biocompatible, non-antigenic, degradable, promote vascular growth, and stimulate osteogenesis. ${ }^{13-16}$

One of the bone substitutes most used in dental surgical procedures and maxillary bone augmentation is beta-tricalcium phosphate $(\beta-\mathrm{TCP})$, which has shown good reported outcomes. ${ }^{17-19}$ It is an osteoconductive material with interconnected pores that create a capillary force to draw cells and nutrients into the material; moreover, $\beta$-TCP is resorbed quickly, followed by new bone formation. ${ }^{20}$ Some authors believe that the use of biomaterials alone cannot provide the ideal structural resistance in the bone, thus compromising osseointegration in the long term. ${ }^{21}$ For this reason, some have proposed mixing the autogenous bone graft with osteoinductive factors to achieve better bone repair in addition to more volume. ${ }^{14,22}$

The volumetric changes achieved with $\beta$-TCP alone, $\beta$-TCP mixed with autogenous bone graft in a 1:1 ratio, and autogenous bone graft alone after 6 months of bone healing have been demonstrated previously. $^{23}$ In that study, a $-38.3 \%$ bone volume change was reported for $\beta$-TCP, $-43.8 \%$ for $\beta$-TCP + autogenous bone graft, and $-45.7 \%$ for autogenous bone graft alone. The similarity of $\beta$-TCP and autogenous bone in relation to the maintenance of bone graft volume, suggested that $\beta$-TCP could be used safely for maxillary sinus augmentation. However, data for bone healing from histomorphometric and immunohistochemical assessments are still required.

Bone healing requires a suitable environment to promote vascular formation in order to supply nutrients and oxygen to the graft. $^{24,25}$ Vascular endothelial growth factor (VEGF) is one of the most important vascular growth factors, because it promotes the migration and proliferation of endothelial cells. ${ }^{26-30}$ Initially, the regulation of bone healing occurs by osteoblastic differentiation, which is mediated by runt-related transcription factor 2 (RUNX2). ${ }^{31}$ RUNX2 transcription is regulated by bone morphogenetic proteins and fibroblastic growth factors in the early stages of osteoblast differentiation. The action of RUNX2 is mediated by pluripotent mesenchymal cells until the final stage of osteoblast differentiation, at which time the process is inhibited. ${ }^{32}$

The aim of this study was to perform a histological evaluation of the healing process following the use of $\beta$-TCP (chronOS; DePuy Synthes, Paoli, CA, USA). The effects of $\beta$-TCP in combination or not with autogenous bone graft (1:1) were compared with the effects of autogenous bone graft alone at 6 months after maxillary sinus augmentation by quantifying the amounts of RUNX2 and VEGF.

The hypotheses of this study were (1) null hypothesis (H0): $\beta$-TCP does not present more new bone formation than autogenous bone graft alone; (2) alternate hypothesis (H1): $\beta$-TCP added to autogenous bone graft $1: 1$ presents more new bone formation than $\beta$-TCP alone.

\section{Materials and methods}

This prospective clinical study was performed at the Araçatuba Dental School UNESP in São Paulo, Brazil, from March 2012 to November 2013, and was approved by the necessary ethics committee. Patients were included in the study if they presented edentulous posterior maxillary bone regions and a bone height of less than $5 \mathrm{~mm}$, which necessitated bone augmentation for dental implant placement. Patients were excluded if they presented uncontrolled systemic problems or local problems, such as uncontrolled periodontitis or a sinus pathology. Smokers and patients who had received radiation treatment in the head and neck region were also excluded. Maxillary and mandibular cone beam computed tomography (CBCT) was performed prior to recruitment in order to evaluate the maxillary sinus and the bone height remaining in the maxillary floor, as well as the retromandibular and mandibular symphysis regions, to determine the volume of the mandible from where the bone grafts would be harvested. Based on these parameters, 22 patients requiring the augmentation of 36 maxillary sinuses were recruited.

Three groups were created for this study: group 1 comprised 12 maxillary sinuses augmented with $\beta$-TCP; group 2 comprised 12 maxillary sinuses augmented with $\beta$-TCP and autogenous bone graft (1:1); group 3 comprised 12 maxillary sinuses augmented with autogenous bone graft alone. There was no association between the side of the maxillary sinus and the graft material used. Randomization was performed by drawing lots to decide which sites would be grafted with each material. This was done by a clinical assistant, who was not involved in the surgeries or in the data evaluation. Two patients did not return for follow-up; thus the final analysis included only nine sinuses for group 2 and 11 for group 1.

\section{Surgical procedures}

All surgical procedures were performed under local anaesthesia using 2\% lidocaine with 1:100,000 epinephrine (Nova DFL, Taquara, RJ, Brazil).

\section{Harvesting bone grafts from mandibular bone}

The autogenous bone graft was removed from the mandibular symphysis as follows: An incision was made in the inferior labial mucosa extending from the canine tooth to the mental muscle. The blade was then tilted towards the bone to incise the muscle and periosteum. The flap was elevated with a Molt No. 9 elevator (Golgran, São Caetano do Sul, SP, Brazil), and the mandibular symphysis bone was exposed and osteotomized with a 701 drill (KG Sorensen, Cotia, SP, Brazil) under constant irrigation with $0.9 \%$ saline solution (Darrow, Rio de Janeiro, RJ, Brazil). The retromolar bone graft site was approached through an intraoral incision, similar to a mandibular sagittal osteotomy, and osteotomized with a 701 drill; the graft was harvested with a chisel. The excised bone block was pulverized with a bone crusher (Neodent, Curitiba, PR, Brazil). 


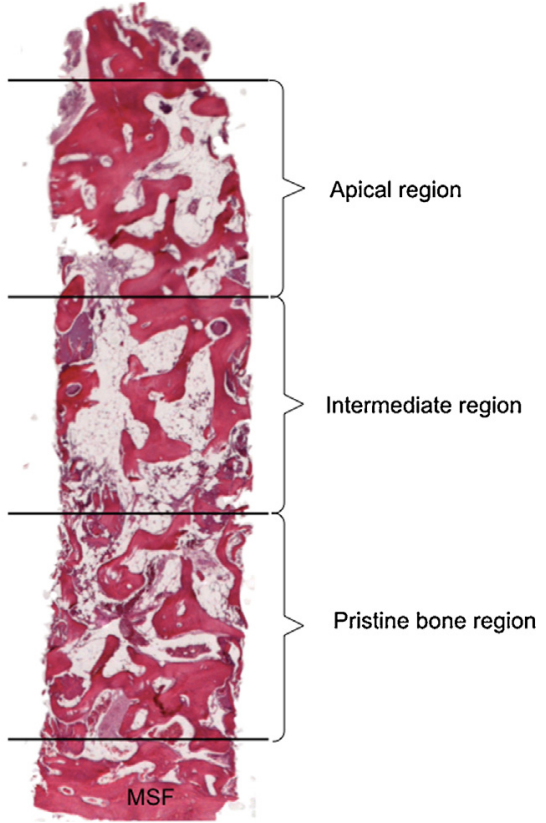

Fig. 1. Histological overview of a biopsy specimen obtained from a maxillary sinus augmented with an autogenous bone graft, demonstrating the three regions studied (MSF, maxillary sinus floor); haematoxylin and eosin stain, $\times 1.25$ magnification.

\section{Maxillary sinus augmentation}

The maxillary sinus was augmented according to the procedure of Boyne and James. ${ }^{33}$ During the first week, all patients were administered $500 \mathrm{mg}$ paracetamol (EMS, São Paulo, SP, Brazil) four times per day to reduce pain and $500 \mathrm{mg}$ amoxicillin (EMS, São Paulo, SP, Brazil) three times per day as antimicrobial prophylaxis to reduce the chance of infection.

\section{Histomorphometric analysis}

Biopsy samples were collected at the time of dental implant placement with a $3.0 \times 15-\mathrm{mm}$ trephine bur $(\mathrm{MK}$ Life, Porto Alegre, RS, Brazil) and stored in $10 \%$ formalin solution $(\mathrm{pH} 7)$ for $48 \mathrm{~h}$. The samples were stored and maintained in the same apical orientation. They were then washed in running water for $24 \mathrm{~h}$ and decalcified in ethylenediaminetetraacetic acid (EDTA) solution for 4 weeks. The solution was changed weekly. Next, samples were embedded in paraffin maintaining the apical orientation, sliced to a thickness of $5 \mu \mathrm{m}$, placed on slides, and stained with haematoxylin and eosin. The biopsies were evaluated by light microscopy and the images were captured using an attached digital camera (JVC TK1270 colour video camera) at $\times 12.5$ magnification. Three regions were identified for

Table 1. Histological outcomes for new bone formation after 6 months of bone repair in the human maxillary sinus with the three biomaterials evaluated.

\begin{tabular}{lccc}
\hline Region & Group 1 (\%) A & Group 2 (\%) B & Group 3 (\%) AB \\
\hline Pristine bone & $46.3 \pm 11.6^{\mathrm{a}}$ & $35.0 \pm 15.8^{\mathrm{b}}$ & $43.1 \pm 16.0^{\mathrm{c}}$ \\
Intermediate & $47.6 \pm 9.9^{\mathrm{a}}$ & $32.5 \pm 13.7^{\mathrm{b}}$ & $31.0 \pm 13.0^{\mathrm{c}}$ \\
Apical & $44.8 \pm 22.1^{\mathrm{a}}$ & $32.8 \pm 16.0^{\mathrm{b}}$ & $46.1 \pm 16.3^{\mathrm{c}}$ \\
\hline
\end{tabular}

Group 1: $\beta$-TCP alone; group 2: $\beta$-TCP mixed with autogenous bone grafts $(1: 1)$; group 3: autogenous bone grafts alone. Data with the same letters (capital for columns, lower case for rows) indicate no statistical difference $(P>0.05)$.

each biopsy specimen: pristine bone ( $2 \mathrm{~mm}$ above the upper side of the maxillary sinus floor), intermediate region, and apical region ( $2 \mathrm{~mm}$ below the Schneiderian membrane). The maxillary sinus floor was considered the most cortical bone in the lower part of the sample following the bone height determination by computed tomography (Fig. 1). New bone and connective tissue formation was analyzed by histomorphometry using a Merz grid added to the images in PowerPoint for Mac (Microsoft, Redmond, WA, USA). ${ }^{34}$ Masson's trichrome staining was used to show the initial stage of bone formation.

\section{Immunohistochemical analysis}

Primary polyclonal goat antibodies raised against human VEGF or RUNX2 were used in the immunohistochemical assays (Santa Cruz Biotechnology, Santa Cruz, CA, USA; catalogue numbers SC1881 and SC8566, respectively). A biotinylated donkey anti-goat secondary antibody (Jackson ImmunoResearch Laboratories, West Grove, PA, USA) coupled to avidin (Vector Laboratories, Burlingame, CA, USA) was used for signal amplification. The binding reaction was detected with diaminobenzidine (Sigma-Aldrich, St Louis, MO, USA), a chromogenic substrate for avidin. The biopsies were divided into the same three regions as used in the histomorphometric evaluation. The data analyses were performed using a single-evaluator semi-quantitative approach, with a score of ' 0 ' indicating the absence of staining and scores of ' 1 ', ' 2 ', and ' 3 ' indicating low, moderate, and intense staining, respectively. ${ }^{35}$

\section{Statistical analysis}

The Shapiro-Wilk test was performed to determine whether the samples had a normal distribution. Comparisons between groups were performed using analysis of variance (ANOVA) followed by Tukey's multiple comparison test (SigmaPlot 12.3; Systat Software, San José, CA, USA). An a priori $P$-value of $<0.05$ was used for all tests.

\section{Results}

\section{Histomorphometry}

The average bone height in the maxillary sinus floor was $3.2 \pm 1.5 \mathrm{~mm}$ in group 1 , $2.6 \pm 1.6 \mathrm{~mm}$ in group 2, and $2.6 \pm 1.3 \mathrm{~mm}$ in group 3 .

The average new bone formation for group 1 was $46.3 \pm 11.6 \%$ in the pristine bone region, $47.6 \pm 9.9 \%$ in the intermediate region, and $44.8 \pm 22.1 \%$ in the apical region (Table 1). The newly formed
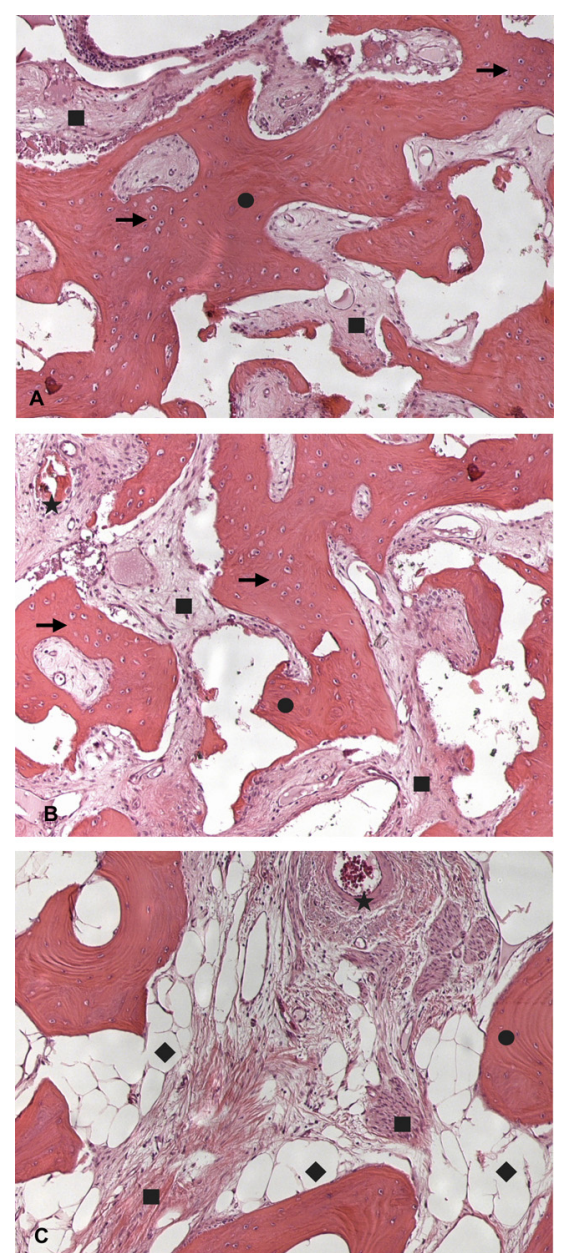

Fig. 2. Images showing a histological section from group 1: (A) pristine bone region, (B) intermediate region, and $(\mathrm{C})$ apical region; haematoxylin and eosin stain, $\times 12.5$ magnification. Newly formed bone (O); connective tissue $(\boldsymbol{\square})$; osteoblast island $(\rightarrow)$; bone marrow $(\diamond)$; blood vessel $(\star)$. 


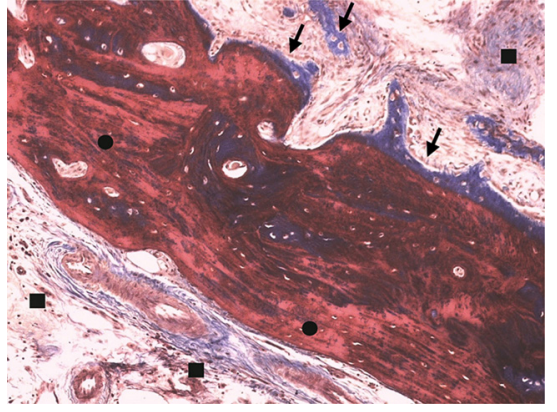

Fig. 3. Masson's trichrome staining of group 1 showing lamellar bone $(\boldsymbol{O})$, a line of new bone formation at the periphery $(\rightarrow)$, and connective tissue $(\boldsymbol{\square}) ; \times 25$ magnification.

bone presented a few woven bone areas and well cellularized connective tissue in all regions studied (Fig. 2). The biopsies of this group showed mature bone and connective tissue that were cellularized and vascularized (Fig. 3).

For group 2, the rate of new bone formation was $35.0 \pm 15.8 \%$ in the pristine bone region, $32.5 \pm 13.7 \%$ in the intermediate region, and $32.8 \pm 16.0 \%$ in the apical region (Table 1). With regard to the histological features, this group presented immature bone formation with woven bone areas and typical trabecular bone of type IV (Figs. 4 and 5).

In group 3, the rate of new bone formation was $43.1 \pm 16.0 \%, 31.0 \pm 13.0 \%$, and $46.1 \pm 16.3 \%$ in the pristine bone region, intermediate region, and apical region, respectively. The bone formed in this group was mature, with osteoblastic cells on the periphery and well cellularized connective tissue (Fig. 6).

No statistically significant difference in bone formation was observed among the three regions within each group $(P>0.05)$. However, there was a statistically significant difference in bone formation between groups 1 and $2(P=0.03)$ (Table 1; Fig. 7).

For group 1, the amount of connective tissue was $48.8 \pm 5.4 \%$ in the pristine bone region, $52.3 \pm 9.9 \%$ in the intermediate region, and $55.1 \pm 22.1 \%$ in the apical region $(P>0.05)$. For group 2, the amounts were $56.8 \pm 9.9 \%$ in the pristine bone region, $60.1 \pm 13.9 \%$ in the
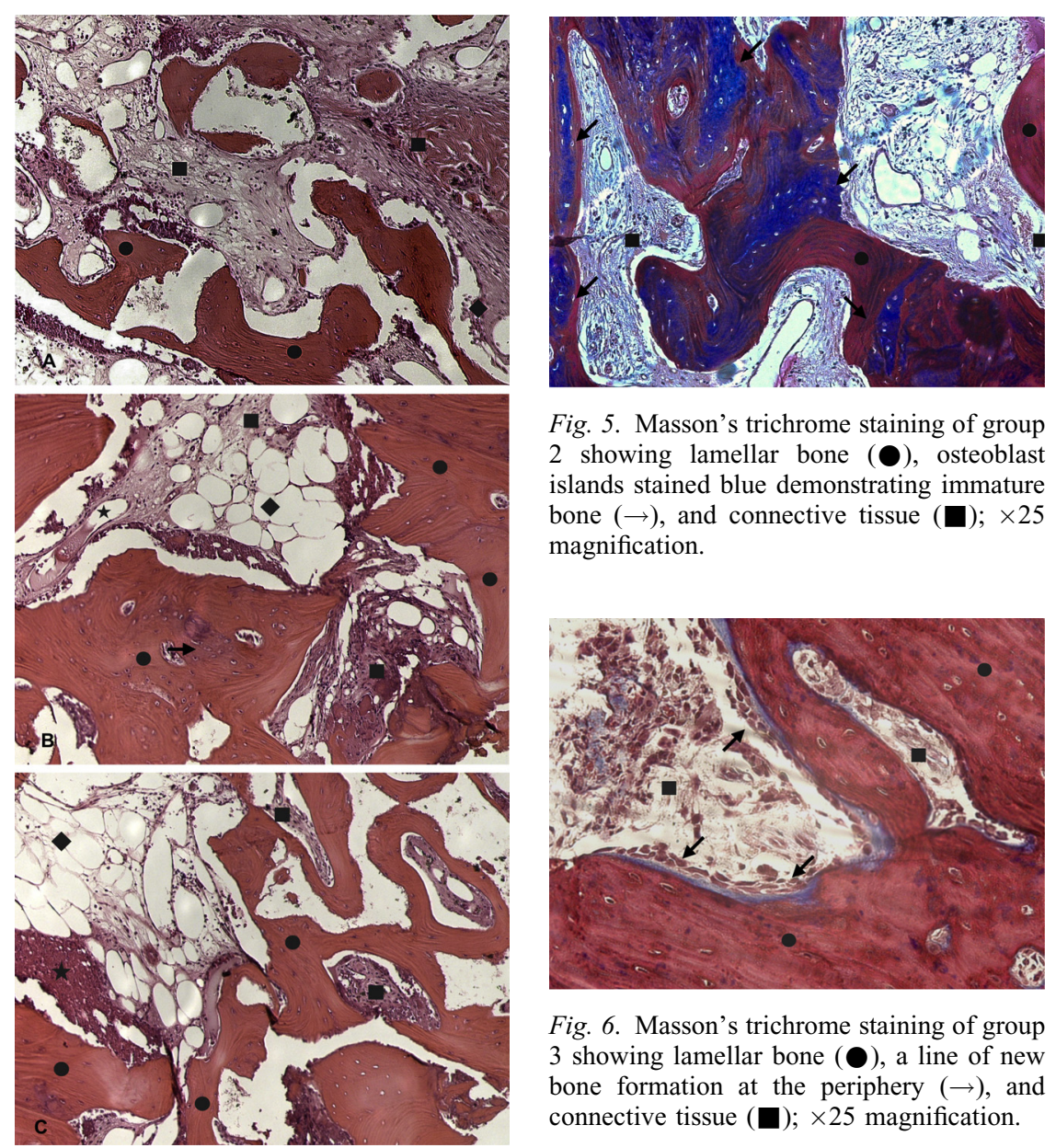

Fig. 4. Images showing a histological section from group 2: (A) pristine bone region, (B) intermediate region, and (C) apical region; haematoxylin and eosin stain, $\times 12.5$ magnification. Newly bone formed (O); connective tissue (ם); a chronOS particle being reabsorbed $(\star)$; bone marrow $(\bullet)$; woven bone $(\rightarrow)$.

intermediate region, and $55.5 \pm 9.2 \%$ in the apical region $(P>0.05)$. The amount of connective tissue found in group 3 was $55.1 \pm 13.6 \%$ in the pristine bone region, $65.0 \pm 10.2 \%$ in the intermediate region, and $50.2 \pm 14.5 \%$ in the apical region $(P>0.05)$ (Table 2).

\section{Immunochemistry}

A single evaluator assigned the scores for the two proteins probed in the three

Table 2. Histological outcomes for connective tissue after 6 months of bone repair in the human maxillary sinus with the three biomaterials evaluated.

\begin{tabular}{lccr}
\hline Region & Group 1 (\%) A & Group 2 (\%) A & Group 3 (\%) A \\
\hline Pristine bone & $48.8 \pm 5.4^{\mathrm{a}}$ & $56.8 \pm 9.9^{\mathrm{b}}$ & $55.1 \pm 13.6^{\mathrm{c}}$ \\
Intermediate & $52.3 \pm 9.9^{\mathrm{a}}$ & $60.1 \pm 13.9^{\mathrm{b}}$ & $65.0 \pm 10.2^{\mathrm{c}}$ \\
Apical & $55.1 \pm 22.1^{\mathrm{a}}$ & $55.5 \pm 9.2^{\mathrm{b}}$ & $50.2 \pm 14.5^{\mathrm{c}}$ \\
\hline
\end{tabular}

Group 1: $\beta$-TCP alone; group 2: $\beta$-TCP mixed with autogenous bone grafts (1:1); group 3: autogenous bone grafts alone. Data with the same letters (capital for columns, lower case for rows) indicate no statistical difference $(P>0.05)$.
Fig. 5. Masson's trichrome staining of group 2 showing lamellar bone $(\mathbf{O})$, osteoblast islands stained blue demonstrating immature bone $(\rightarrow)$, and connective tissue $(\boldsymbol{\square}) ; \times 25$ magnification.

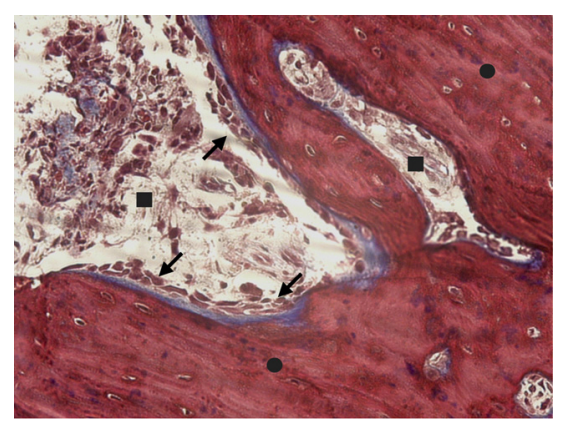

Fig. 6. Masson's trichrome staining of group 3 showing lamellar bone $(\mathbf{O})$, a line of new bone formation at the periphery $(\rightarrow)$, and connective tissue $(\boldsymbol{\square}) ; \times 25$ magnification.

groups. In group 1, the intensity was low (' 1 ') for preosteoblastic cells immunostained for RUNX2 in connective tissue in the pristine bone, intermediate, and apical regions (Fig. 8). For group 2, immunostaining for RUNX2 was moderate (' 2 ') in all regions, with cells presenting an osteoblastic phenotype next to the periphery bone and in the connective tissue (Fig. 9). In group 3, a low ('1') level of RUNX2-positive staining was observed in all regions (Fig. 10) (Table 3).

The immunostaining for VEGF was moderate (' 2 ') in all regions in group 1 (Fig. 11) and intense (' 3 ') in all regions in group 2 (Fig. 12). In group 3, low (' 1 ') VEGF-positive staining was observed in cells in the pristine bone region, but moderate (' 2 ') in the intermediate and apical regions (Fig. 13) (Table 4).

\section{Discussion}

$\beta$-TCP is an alloplastic material that is rapidly resorbed. This differs from hydroxyapatite, which has a low or absent resorption capacity. ${ }^{36}$ chronOS granules range in size from $0.5 \mathrm{~mm}$ to $0.7 \mathrm{~mm}$ and have $60 \%$ porosity. According to Karageorgiou and 


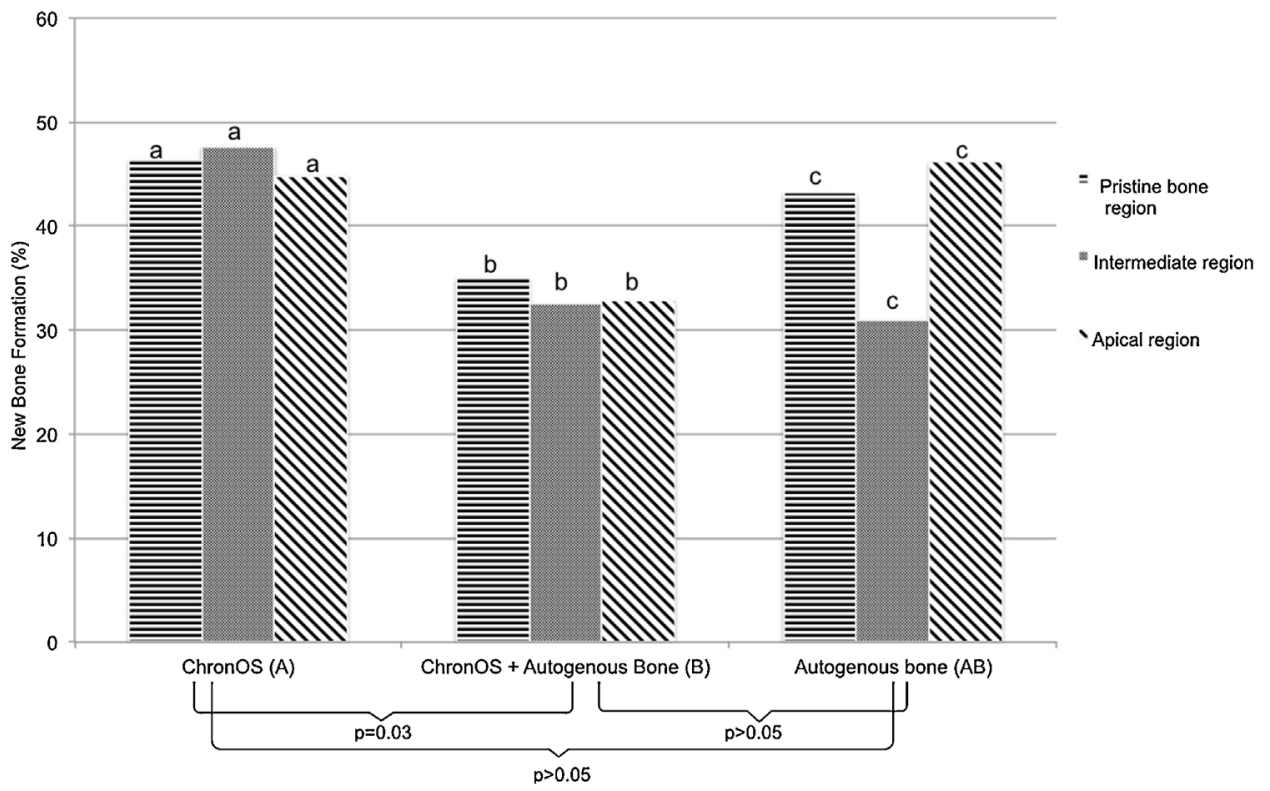

Fig. 7. Graph showing the histomorphometric outcomes for new bone formation after 6 months of bone repair in the human maxillary sinus augmented with $\beta$-TCP (chronOS), $\beta$-TCP (chronOS) + autogenous bone graft $(1: 1)$, and pure autogenous bone graft. Data with the same letters (capital for each group, lower case for columns) indicate no statistical difference $(P>0.05)$.
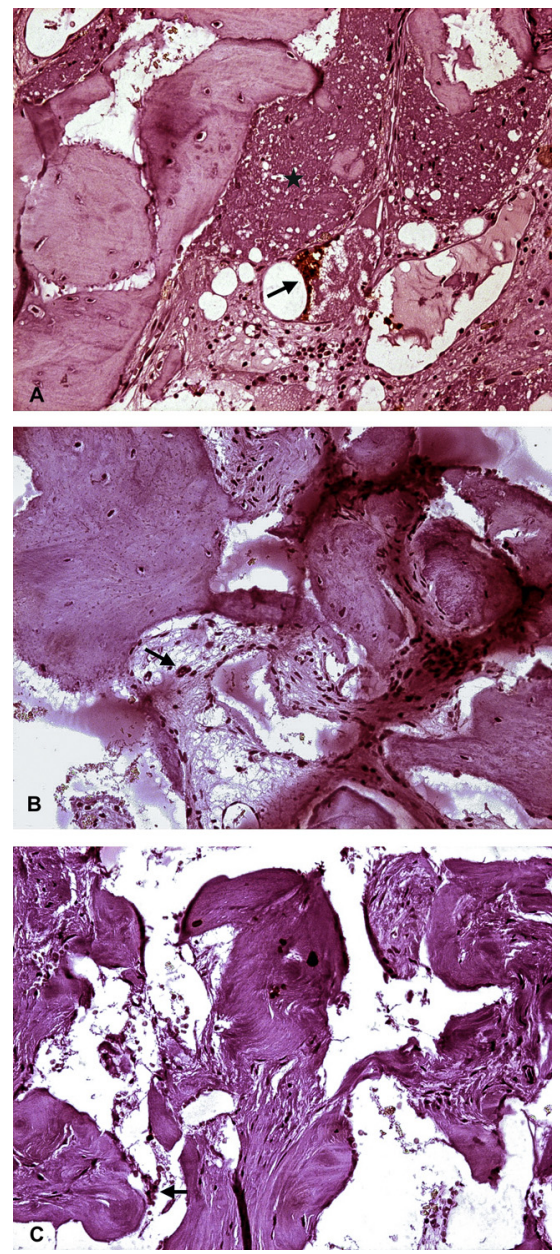

Fig. 8. Histological section showing positive immunolabelling for RUNX2 $(\rightarrow)$ in group 1: (A) pristine bone region, (B) intermediate region, and $(C)$ apical region; Harris's haematoxylin stain, B-TCP granule $(\star), \times 25$ magnification.
Table 3. Immunolabelling scores for RUNX2.

\begin{tabular}{lccc}
\hline Region & Group 1 & Group 2 & Group 3 \\
\hline Pristine bone & 1 & 2 & 1 \\
Intermediate & 1 & 2 & 1 \\
Apical & 1 & 2 & 1
\end{tabular}

RUNX2, runt-related transcription factor 2 . Group 1: $\beta$-TCP alone; group 2: $\beta$-TCP mixed with autogenous bone grafts (1:1); group 3 : autogenous bone grafts alone.

Table 4. Immunolabelling scores for VEGF.

\begin{tabular}{lccc}
\hline Region & Group 1 & Group 2 & Group 3 \\
\hline Pristine bone & 2 & 3 & 1 \\
Intermediate & 2 & 3 & 2 \\
Apical & 2 & 3 & 2 \\
\hline
\end{tabular}

VEGF, vascular endothelial growth factor. Group 1: $\beta$-TCP alone; group 2: $\beta$-TCP mixed with autogenous bone grafts (1:1); group 3 : autogenous bone grafts alone.

Kaplan, the ideal $\beta$-TCP pore size should be $>50 \mu \mathrm{m}$ diameter $^{37}$; chronOS $\beta$-TCP pores range from $100 \mu \mathrm{m}$ to $400 \mu \mathrm{m}$ and thus provide good structural quality.

Many researchers consider the autogenous bone graft to be the most favourable for bone reconstruction. ${ }^{7,38,39}$ However, successful outcomes have been shown with the use of $\beta$-TCP in maxillary sinus augmentation, with bone formation ranging from $29 \%$ to $40.7 \%$. ${ }^{14,16,22,40-42}$ In the present study, the rate of new bone formation was $46.3 \%$ in the pristine bone region, $47.6 \%$ in the intermediate region, and $44.8 \%$ in the apical region with the use of $\beta$-TCP alone. This indicates that $\beta$-TCP
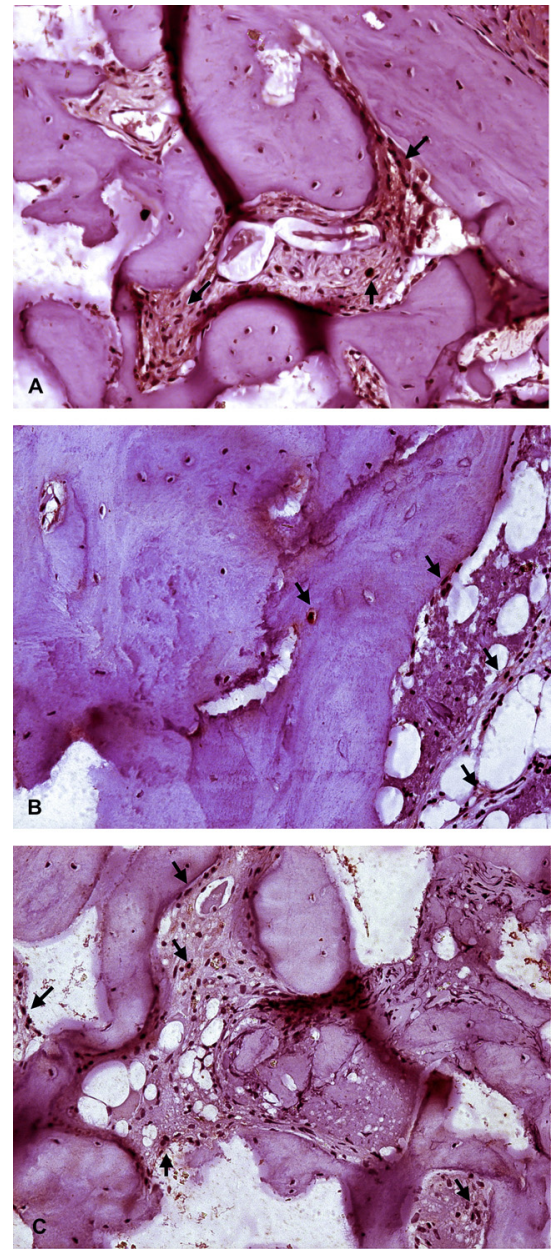

Fig. 9. Histological section showing positive immunolabelling for RUNX2 $(\rightarrow)$ in group 2 : (A) pristine bone region, (B) intermediate region, and $(\mathrm{C})$ apical region; Harris's haematoxylin stain, $\times 25$ magnification. 

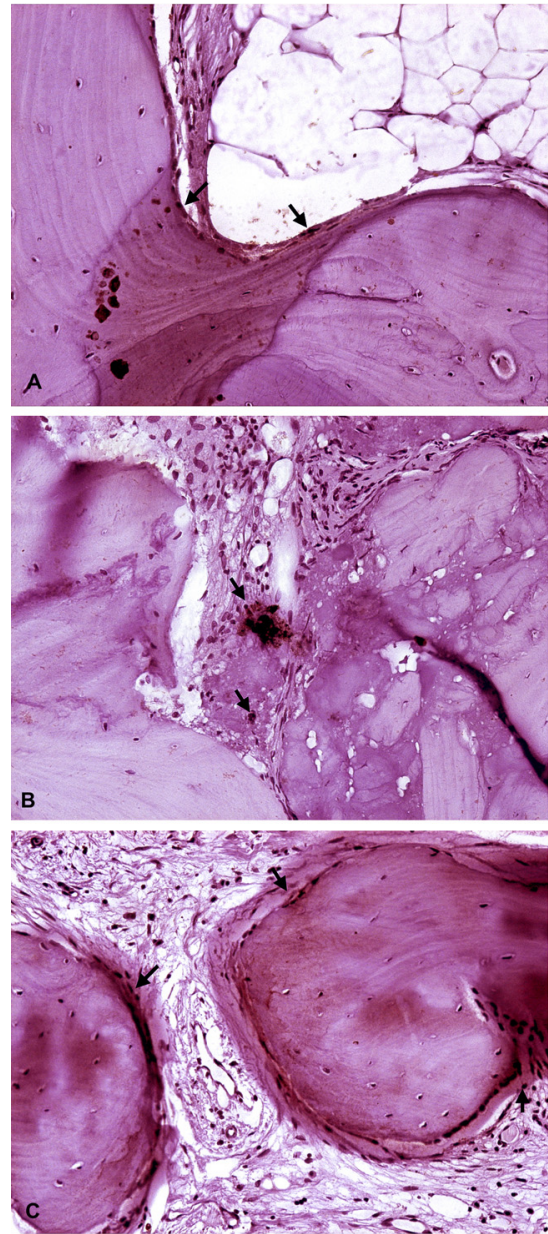

Fig. 10. Histological section showing positive immunolabelling for RUNX2 $(\rightarrow)$ in group 3: (A) pristine bone region, (B) intermediate region, and $(\mathrm{C})$ apical region; Harris's haematoxylin stain, $\times 25$ magnification.

is a good bone substitute in maxillary sinus augmentation.

The addition of autogenous bone graft to biomaterials leads to the release of osteoinductor components more than organic components. ${ }^{7,43,44}$ Yildirim et al. evaluated bone formation using a composite graft consisting of Bio-Oss and autogenous bone graft in maxillary sinus augmentation over periods ranging from 4 months to 36 months. ${ }^{10}$ Their results showed $18.9 \%$ bone formation and $29.6 \%$ of the biomaterial remaining. Turunen et al. obtained better outcomes using bioactive glass added to autogenous bone graft than with autogenous bone graft alone. ${ }^{45}$ In a study using micro-computed tomography, they found $28.8 \%$ and $34 \%$ of the bone in contact with the remaining biomaterial particle.

Miyamoto et al. used a composite graft of $\beta$-TCP and autogenous bone to reconstruct the posterior maxillary region. ${ }^{46}$ Biopsies were harvested at the lateral wall,
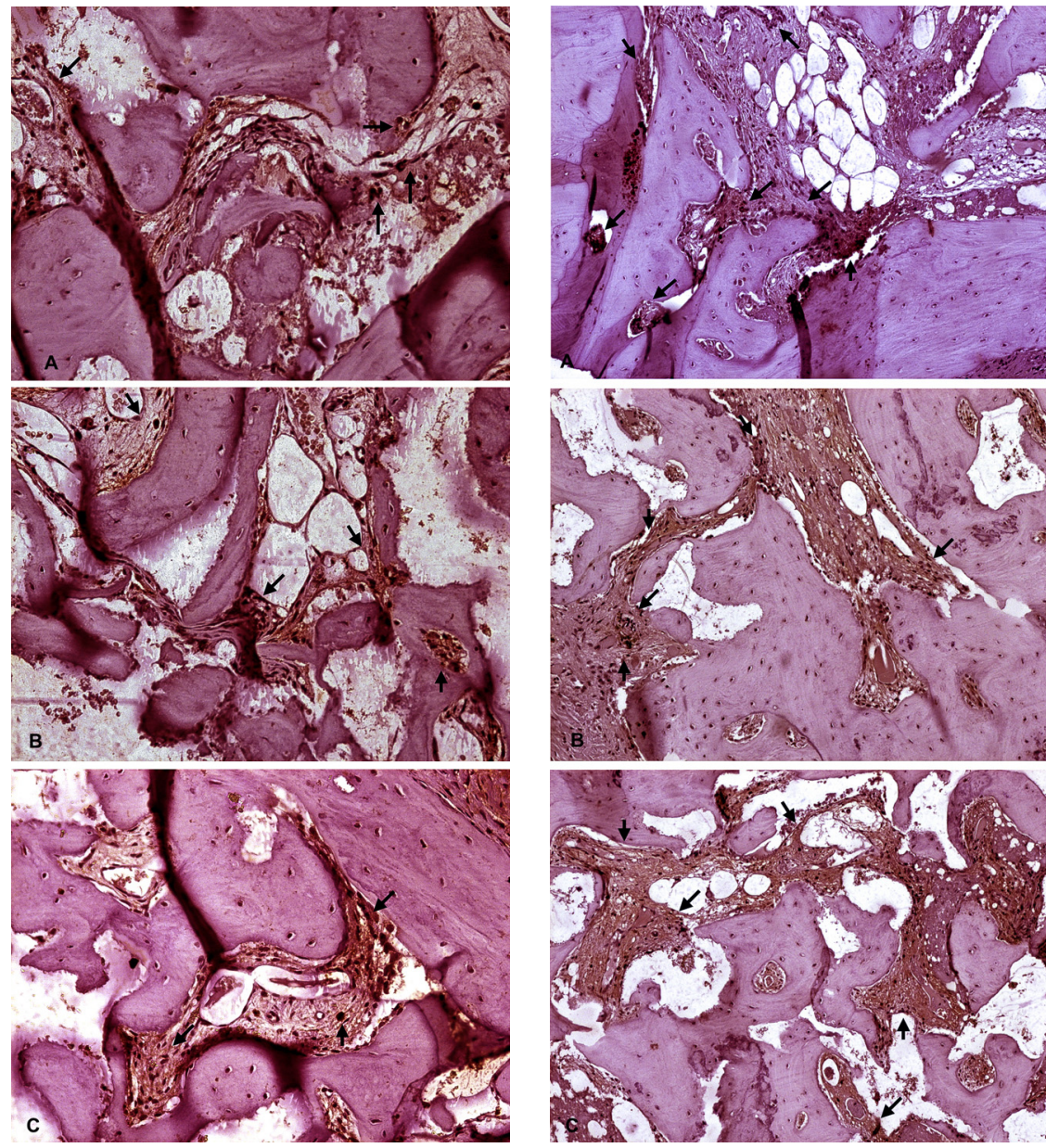

Fig. 11. Histological section showing positive immunolabelling for VEGF $(\rightarrow)$ in group 1: (A) pristine bone region, (B) intermediate region, and (C) apical region; Harris's haematoxylin stain, $\times 25$ magnification.

inclined in an apical direction. Bone formation next to these regions was evaluated. They found $42 \%$ of bone in the lateral wall region and $34 \%$ in the apical region. The results of the present study showed $35.0 \%$ in the pristine bone region, $32.5 \%$ in the intermediate region, and $32.8 \%$ in the apical region, which is in agreement with their results.

The aim of all bone grafts is to provide a 3D scaffold to support cellular migration and vascular penetration during the healing phase. ${ }^{5,20}$ The first step in this phase is angiogenesis. VEGF is one of several proteins that regulate the development and repair of bone. ${ }^{47}$ It is responsible for endothelial cell differentiation, the stimulation of vascular proliferation, and the attraction of osteoblastic cells during bone graft maturation. ${ }^{26,48}$ RUNX2 is responsible for upregulating preosteoblasts and collagen type 1 production during bone repair. ${ }^{31,49}$ These proteins were detected in immuno-probed connective

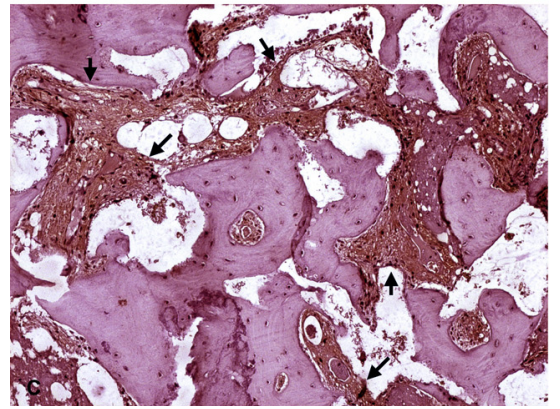

Fig. 12. Histological section showing positive immunolabelling for VEGF $(\rightarrow)$ in group 2: (A) pristine bone region, (B) intermediate region, and $(\mathrm{C})$ apical region; Harris's haematoxylin stain, $\times 12.5$ magnification.

tissue cells, indicating an osteoblastic phenotype.

In the present study, group 3 displayed a remodelling phase due to the activities of RUNX2 and VEGF in all regions. Comparison with group 1 suggested that the bone formed was in a remodelling phase like that in group 3. The moderate expression of VEGF indicated increased vascular formation activity, as seen in the histomorphometric results, which was similar in the two groups. Group 2 presented a delay in bone formation when $\beta$-TCP was added to the autogenous bone graft. Immunostaining for both proteins showed a high cellular activity in the connective tissue after 6 months of bone healing. These data demonstrate that the graft possessed sufficient activity for bone formation, which is in agreement with the results of Miyamoto et al. ${ }^{46}$

It has been demonstrated previously that $\beta$-TCP results in the same volumetric changes when used alone or when added to 


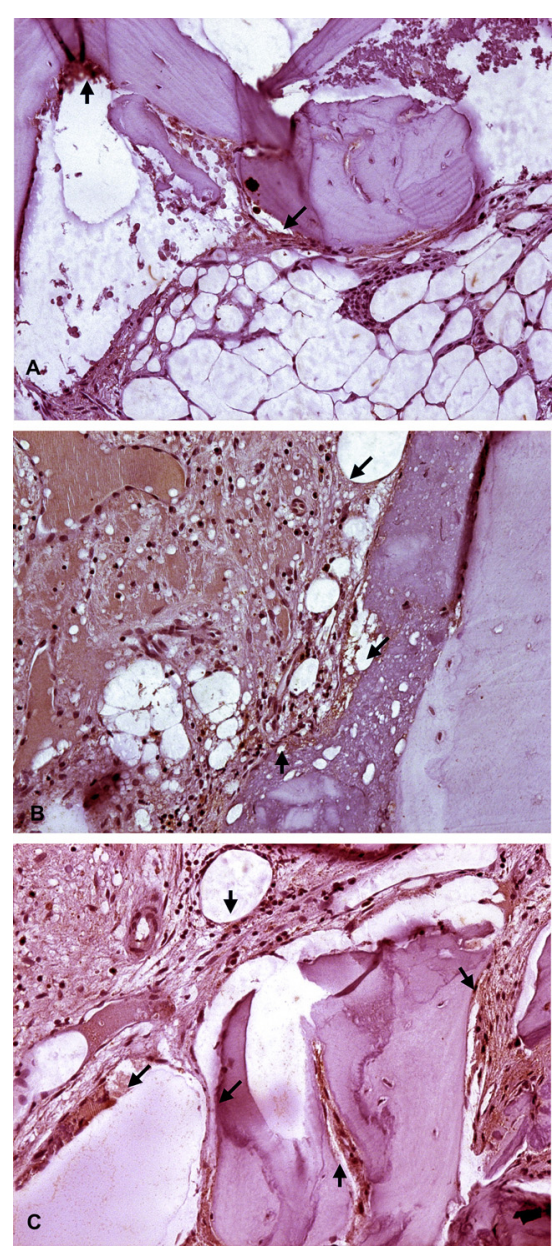

Fig. 13. Histological section showing positive immunolabelling for VEGF $(\rightarrow)$ in group 3: (A) pristine bone region, (B) intermediate region, and $(\mathrm{C})$ apical region; Harris's haematoxylin stain, $\times 25$ magnification.

autogenous bone graft of pure autogenous bone. $^{23}$ Taken together, the results of both studies confirm that $\beta$-TCP can be used safely, without the need for a donor site, minimizing the risks and avoiding morbidity. The authors believe that the use of a mixed bone graft is only necessary when a large amount of graft is required. However, the group that received the biomaterial and autogenous bone graft still acquired a sufficient volume to place dental implants, even though less bone was formed. It is inferred that the bone was still repairing, as suggested by the number of cells with osteogenic capacity that were present after 6 months.

In conclusion, this study showed that $\beta$ TCP presents the same behaviour as an autogenous bone graft, which makes it a good bone substitute. However, when both biomaterials are mixed, a delay in bone healing is observed, although osteogenic activity is still present. Thus, both hypotheses $\mathrm{H} 0$ and $\mathrm{H} 1$ are rejected.

\section{Funding}

We thank FAPESP for the financial support, which enabled the authors to develop this study (process numbers 2012/08455-4 and 2012/10028-7).

\section{Competing interests}

The authors declare no conflicts of interest.

\section{Ethical approval}

This study followed the ethical principles for human experimentation of the Araçatuba Dental School - UNESP (number 132917, reported 5/11/2012). This study was approved by the ethics committee (number 03416512.7.0000.5420).

\section{Patient consent}

Not required.

\section{References}

1. Moon JW, Sohn DS, Heo JU, Shin HI, Jung JK. New bone formation in the maxillary sinus using peripheral venous blood alone. $J$ Oral Maxillofac Surg 2011;69:2357-67.

2. Smiler DG, Johnson PW, Lozada JL, Misch C, Rosenlicht JL, Tatum Jr OH et al. Sinus lift grafts and endosseous implants. Treatment of the atrophic posterior maxilla. Dent Clin North Am 1992;36:151-86.

3. Esposito M, Grusovin MG, Rees J, Karasoulos D, Felice P, Alissa R, et al. Effectiveness of sinus lift procedures for dental implant rehabilitation: a Cochrane systematic review. Eur J Oral Implantol 2010;3:7-26.

4. Tatum HJ. Maxillary and sinus implant reconstructions. Dent Clin North Am 1986;30:207-29.

5. Walsh WR, Vizesi F, Michael D, Auld J, Langdown A, Oliver R, et al. Beta-TCP bone graft substitutes in a bilateral rabbit tibial defect model. Biomaterials 2008;29:266-71.

6. Cypher TJ, Grossman JP. Biological principles of bone graft healing. J Foot Ankle Surg 1996;35:413-7.

7. Misch CE. Maxillary sinus augmentation for endosteal implants: organized alternative treatment plans. Int $J$ Oral Implantol 1987;4:49-58.

8. Moy PK, Lundgren S, Holmes RE. Maxillary sinus augmentation-histomorphometric analysis of graft materials for maxillary sinus floor augmentation. $J$ Oral Maxillofac Surg 1993;51:857-62.

9. Wood RM, Moore DL. Grafting of the maxillary sinus with intraorally harvested autog- enous bone prior to implant placement. Int $J$ Oral Maxillofac Implants 1988;3:209-14.

10. Yildirim M, Spiekermann H, Handt S, Edelhoff D. Maxillary sinus augmentation with the xenograft Bio-Oss and autogenous intraoral bone for qualitative improvement of the implant site: a histologic and histomorphometric clinical study in humans. Int J Oral Maxillofac Implants 2001;16: 23-33.

11. Rickert D, Slater JJ, Meijer HJ, Vissink A, Raghoebar GM. Maxillary sinus lift with solely autogenous bone compared to a combination of autogenous bone and growth factors or (solely) bone substitutes. A systematic review. Int J Oral Maxillofac Surg 2012;41:160-7.

12. Kingsmill VJ, Boyde A, Jones SJ. The resorption of vital and devitalized bone in vitro: significance for bone grafts. Calcif Tissue Int 1999;64:252-6.

13. Neamat A, Gawish A, Gamal-Eldeen AM. beta-Tricalcium phosphate promotes cell proliferation, osteogenesis and bone regeneration in intrabony defects in dogs. Arch Oral Biol 2009;54:1083-90.

14. Szabó G, Huys L, Coulthard P, Maiorana C, Garagiola U, Barabás J, et al. A prospective multicenter randomized clinical trial of autogenous bone versus beta-tricalcium phosphate graft alone for bilateral sinus elevation: histologic and histomorphometric evaluation. Int $J$ Oral Maxillofac Implants 2005;20:371-81.

15. Wheeler SL, Holmes RE, Calhoun CJ. Sixyear clinical and histologic study of sinus-lift grafts. Int $J$ Oral Maxillofac Implants 1996;11:26-34.

16. Zijderveld SA, Zerbo IR, van den Bergh JP, Schulten EA, ten Bruggenkate CM. Maxillary sinus floor augmentation using a $\beta$ tricalcium phosphate (Cerasorb) alone compared to autogenous bone grafts. Int J Oral Maxillofac Implants 2005;20:432-40.

17. Suba Z, Takacs D, Matusovits D, Barabas J, Fazekas A, Szabo G. Maxillary sinus floor grafting with beta-tricalcium phosphate in humans: density and microarchitecture of the newly formed bone. Clin Oral Implants Res 2006;17:102-8.

18. Zerbo IR, Bronckers AL, de Lange G, Burger EH. Localisation of osteogenic and osteoclastic cells in porous beta-tricalcium phosphate particles used for human maxillary sinus floor elevation. Biomaterials 2005;26:1445-51.

19. Zerbo IR, Zijderveld SA, de Boer A, Bronckers AL, de Lange G, ten Bruggenkate CM, et al. Histomorphometry of human sinus floor augmentation using a porous beta-tricalcium phosphate: a prospective study. Clin Oral Implants Res 2004;15:724-32.

20. Knabe C, Koch C, Rack A, Stiller M. Effect of beta-tricalcium phosphate particles with varying porosity on osteogenesis after sinus floor augmentation in humans. Biomaterials 2008;29:2249-58. 
21. Jensen T, Schou S, Gundersen HJ, Forman JL, Terheyden H, Holmstrup P. Bone-to-implant contact after maxillary sinus floor augmentation with Bio-Oss and autogenous bone in different ratios in mini pigs. Clin Oral Implants Res 2013;24:635-44.

22. Cosso MG, de Brito Jr RB, Piattelli A, Shibli JA, Zenobio EG. Volumetric dimensional changes of autogenous bone and the mixture of hydroxyapatite and autogenous bone graft in humans maxillary sinus augmentation. A multislice tomographic study. Clin Oral Implants Res 2013;15:1-6.

23. Gorla LF, Spin-Neto R, Booss FB, Pereira RD, Garcia IR, Hochuli-Vieira E. Use of autogenous bone and beta-tricalcium phosphate in maxillary sinus lifting: a prospective, randomized, volumetric computed tomography study. Int J Oral Maxillofac Surg 2015;44:1486-91.

24. Kempen DH, Lu L, Heijink A, Hefferan TE, Creemers LB, Maran A, et al. Effect of local sequential VEGF and BMP-2 delivery on ectopic and orthotopic bone regeneration. Biomaterials 2009;14:2816-25.

25. Kwon TG, Zhao X, Yang Q, Li Y, Ge C, Zhao G, et al. Physical and functional interactions between Runx 2 and HIF- $1 \alpha$ induce vascular endothelial growth factor gene expression. J Cell Biochem 2011;12:3582-93.

26. De Souza Nunes LS, De Oliveira RV, Holgado LA, Nary Filho H, Ribeiro DA, Matsumoto MA. Immunoexpression of Cbfa-1/ Runx2 and VEGF in sinus lift procedures using bone substitutes in rabbits. Clin Oral Implants Res 2010;21:584-90.

27. Degidi M, Artese L, Rubini C, Perrotti V, Iezzi G, Piattelli A. Microvessel density in sinus augmentation procedures using anorganic bovine bone and autologous bone: 3 months results. Implant Dent 2007;16:31725.

28. Mayr-Wohlfart U, Waltenberger J, Hausser H, Kessler S, Gunther KP, Dehio C, et al. Vascular endothelial growth factor stimulates chemotactic migration of primary human osteoblasts. Bone 2002;30:472-7.

29. Street J, Bao M, deGuzman L, Bunting S, Peale Jr FV, Ferrara N, et al. Vascular endothelial growth factor stimulates bone repair by promoting angiogenesis and bone turnover. Proc Natl Acad Sci U $S$ A 2002;99:9656-61.

30. Degidi M, Artese L, Rubini C, Perrotti V, Iezzi G, Piattelli A. Microvessel density and vascular endothelial growth factor expres- sion in sinus augmentation using Bio-Oss Oral Dis 2006;12:469-75.

31. Cohen MM. Perspectives on RUNX genes: an update. Am J Med Genet A 2009;149A 2629-46.

32. Komori T. Runx2, a multifunctional transcription factor in skeletal development. $J$ Cell Biochem 2002;87:1-8.

33. Boyne PJ, James RA. Grafting of the maxillary sinus floor with autogenous marrow and bone. J Oral Surg 1980;38:613-6.

34. Merz WA. Die Streckenmessung an gerichteten Strukturen im Mikroskop und ihre Anwendung zur Bestimmung von Oberflachen-Volumen-Relationen im Knochengewebe. Mikroskopie 1968;22:132-42.

35. Hawthorne AC, Xavier SP, Okamoto R, Salvador SL, Antunes AA, Salata LA. Immunohistochemical, tomographic, and histological study on onlay bone graft remodeling. Part III: allografts. Clin Oral Implants Res 2013;24:1164-72.

36. Kurkcu M, Benlidayi ME, Cam B, Sertdemir Y. Anorganic bovine-derived hydroxyapatite vs beta-tricalcium phosphate in sinus augmentation: a comparative histomorphometric study. $J$ Oral Implantol 2012;38(Spec No):519-26.

37. Karageorgiou V, Kaplan D. Porosity of 3D biomaterial scaffolds and osteogenesis. Biomaterials 2005;26:5474-91.

38. Hirsch JM, Ericsson I. Maxillary sinus augmentation using mandibular bone grafts and simultaneous installation of implants. A surgical technique. Clin Oral Implants Res 1991;2:91-6.

39. Raghoebar GM, Brouwer TJ, Reintsema H, Vanoort RP. Augmentation of the maxillary sinus floor with autogenous bone for the placement of endosseous implants: a preliminary report. $J$ Oral Maxillofac Surg 1993;51:1198-203.

40. Horch HH, Sader R, Pautke C, Neff A, Deppe H, Kolk A. Synthetic, pure-phase beta-tricalcium phosphate ceramic granules (Cerasorb) for bone regeneration in the reconstructive surgery of the jaws. Int J Oral Maxillofac Surg 2006;35:708-13.

41. Martinez A, Franco J, Saiz E, Guitian F. Maxillary sinus floor augmentation on humans: packing simulations and 8 months histomorphometric comparative study of anorganic bone matrix and beta-tricalcium phosphate particles as grafting materials. Mater Sci Eng C Mater Biol Appl 2010;30:763-9.
42. Somanathan RV, Simunek A. Evaluation of the success of beta-tricalcium phosphate and deproteinized bovine bone in maxillary sinus augmentation using histomorphometry: a review. Acta Medica (Hradec Kralove) 2006;49:87-9.

43. Cordioli G, Mazzocco C, Schepers E, Brugnolo E, Majzoub Z. Maxillary sinus floor augmentation using bioactive glass granules and autogenous bone with simultaneous implant placement. Clinical and histological findings. Clin Oral Implants Res 2001;12:270-8.

44. Rickert D, Vissink A, Slot WJ, Sauerbier S, Meijer HJ, Raghoebar GM. Maxillary sinus floor elevation surgery with BioOss mixed with a bone marrow concentrate or autogenous bone: test of principle on implant survival and clinical performance. Int J Oral Maxillofac Surg 2014;43:243-7.

45. Turunen T, Peltola J, Yli-Urpo A, Happonen RP. Bioactive glass granules as a bone adjunctive material in maxillary sinus floor augmentation. Clin Oral Implants Res 2004; 15:135-41.

46. Miyamoto S, Shinmyouzu K, Miyamoto I, Takeshita K, Terada T, Takahashi T. Histomorphometric and immunohistochemical analysis of human maxillary sinus floor augmentation using porous $\beta$-tricalcium phosphate for dental implant treatment. Clin Oral Implants Res 2013;24:134-8.

47. Jacobsen KA, Al-Aql ZS, Wan C, Fitch JL, Stapleton SN, Mason ZD, et al. Bone formation during distraction osteogenesis is dependent on both VEGFR1 and VEGFR2 signaling. J Bone Miner Res 2008;23:596609.

48. Hsiong SX, Mooney DJ. Regeneration of vascularized bone. Periodontol 2000 2006;41:109-22.

49. Pratap J, Galindo M, Zaidi SK, Vradii D, Bhat BM, Robinson JA, et al. Cell growth regulatory role of Runx 2 during proliferative expansion of preosteoblasts. Cancer Res 2003;63:5357-62.

Address:

Rodrigo dos Santos Pereira

Zeferino Street 243

Mesquita

Rio de Janeiro 26551-081

Brazil

Tel: +55021969375841

E-mail:dr.pereira@live.com 